\title{
Spot urine-guided salt reduction is effective in Japanese cardiology outpatients
}

This article has been corrected since advance Online Publication, and a corrigendum is also printed in this issue.

\author{
Shinichi Hirota ${ }^{1}$, Tsuneaki Sadanaga ${ }^{1,2}$, Hideo Mitamura ${ }^{3}$ and Keiichi Fukuda ${ }^{2}$
}

Dietary salt restriction is recommended for the prevention of cardiovascular disease in patients with hypertension and heart failure as well as in the general population. However, salt reduction is very difficult without knowing the daily salt intake of individual patients. A total of 524 subjects (72 \pm 10 year old, 246 female) who visited an outpatient cardiology clinic were included in this study. Daily dietary salt intake was estimated based on the sodium and creatinine concentrations of spot urine at the time of enrollment and during follow-up for 8-26 weeks. The attending physicians explained the individual data to the patients and encouraged them to reduce their salt intake through simple counseling. The baseline estimated salt excretion was $9.6 \pm 2.7$ (range: $3.5-22.1) \mathrm{g}$ per day, which decreased to $8.7 \pm 2.3$ (3.7-18.0) g per day during follow-up. The systolic blood pressure decreased from $127.0 \pm 15.4$ (range: $80-170)$ to $125.6 \pm 14.5(80-172) \mathrm{mm} \mathrm{Hg}(P=0.026)$, and the diastolic blood pressure decreased from $73.4 \pm 11.0$ (range: $40-106)$ to $71.5 \pm 10.8(50-102) \mathrm{mm} \mathrm{Hg}(P<0.001)$. In conclusion, the estimation of salt intake by spot urine was a useful method for motivating patients to reduce their salt intake; however, achieving salt reduction to the level recommended by the guideline could be a challenge.

Hypertension Research (2012) 35, 1069-1071; doi:10.1038/hr.2012.98; published online 5 July 2012

Keywords: blood pressure; diet; sodium

\section{INTRODUCTION}

Dietary salt restriction is recommended for the prevention of cardiovascular disease in patients with hypertension and heart failure as well as in the general population. ${ }^{1,2}$ At the population level, the voluntary regulation of salt reduction by food industries is important. $^{1,2}$ Focusing on dietary advice for individuals, salt reduction is very difficult to achieve without knowing the daily salt intake of each patient. For the evaluation of salt intake, an estimation based on sodium $(\mathrm{Na})$ content in 24 -h pooled urine is reliable and has been used in many clinical trials, ${ }^{3-6}$ but this method is difficult to perform in outpatients in daily medical practice. In contrast, the evaluation of salt intake using the $\mathrm{Na}$ concentration in a spot urine sample is very easy to perform. In this study, we evaluated the efficacy of salt reduction using a spot urine-guided approach in the outpatient cardiology clinic of a community hospital.

\section{METHODS}

This study was a secondary analysis of the prospectively collected data of 679 patients who visited the outpatient cardiology clinic of Ueki Hospital, Kumamoto, Japan, between September 2009 and November 2011. The study protocol was approved by the institutional ethics committee of the hospital, and informed consent was obtained from all of the patients. The excluded patients were: (a) patients with apparent decompensated heart failure or New
York Heart Association Class $\geqslant$ III heart failure symptoms, despite optimal medical therapies; and (b) patients who needed to change medications during follow-up at the discretion of their attending physicians.

Blood pressure was measured manually by the attending physician with a sphygmomanometer with the patient in the sitting position after at least $10 \mathrm{~min}$ of rest in the waiting room. Three measurements were obtained and the mean of the last two measurements was used for analysis. Body weight and laboratory tests, including urinary $\mathrm{Na}$ and creatinine $(\mathrm{Cr})$, were also measured at the time of enrolment. The attending physicians explained the individual data to the patients and encouraged them to reduce their salt intake through simple counseling, which was specific for Japanese patients, and entailed recommendations to reduce their miso soup (1.5-2.5 g salt per cup) intake from 3 cups to 1 cup per day or to limit the use of soy sauce. The estimated glomerular filtration rate was calculated according to the modified version of the Modification of Diet in Renal Disease Study equation published by the Japanese Society of Nephrology. ${ }^{7}$ Hypertension was defined as systolic blood pressure $\geqslant 140 \mathrm{~mm} \mathrm{Hg}$, diastolic blood pressure $\geqslant 90 \mathrm{~mm} \mathrm{Hg}$ or the use of antihypertensive medications. Diabetes mellitus was defined as fasting plasma glucose $\geqslant 126 \mathrm{mg} \mathrm{dl}^{-1}$, casual glucose level $\geqslant 200 \mathrm{mg} \mathrm{dl}^{-1}$, the use of oral hypoglycemic medications or the use of insulin.

\section{Estimation of salt excretion}

Daily salt excretion was estimated using the following equation: ${ }^{8,9}$

Estimated 24-h urinary salt excretion $(\mathrm{g}$ per day $)=1.285 \times\left(\mathrm{Na}\left(\mathrm{mEql}^{-1}\right) /\right.$ $\mathrm{Cr}\left(\mathrm{mgl}^{-1}\right)$ in spot urine $\times$ expected $24-\mathrm{h}$ Cr excretion $)^{0.392}$, where expected

${ }^{1}$ Division of Cardiology, Ueki Hospital, Kumamoto, Japan; ${ }^{2}$ Department of Cardiology, Keio University School of Medicine, Tokyo, Japan and ${ }^{3}$ Saiseikai Central Hospital, Tokyo, Japan

Correspondence: Dr T Sadanaga, Division of Cardiology, Ueki Hospital, Iwano 285-29, Ueki, Kita-Ku, Kumamoto 861-0136, Japan.

E-mail: kamefu@rb3.so-net.ne.jp

Received 18 March 2012; revised 4 April 2012; accepted 25 April 2012; published online 5 July 2012 
24-h Cr excretion $(\mathrm{mg}$ per day $)=-2.04 \times$ age $($ year old $)+14.89 \times$ weight $(\mathrm{kg})+16.14 \times$ height $(\mathrm{cm})-2244.45$.

The spot urine was collected at the time of the office visits, between 09:00 and 11:00 hours.

\section{Validation of equation to estimate daily urinary salt excretion from $\mathrm{Na}$ concentration of spot urine}

To validate the accuracy of the above-mentioned estimation of salt intake used in this study, urinary samples were obtained by the same method from patients who were admitted to Ueki Hospital, mainly for rehabilitation after orthopedic surgery or bone fractures. These patients received meals containing known amounts of salt for more than 1 week. The salt content in the hospital meals was strictly determined by calculating the ingredients of each food product. The patients were instructed to eat whole meals that were given to them and were not allowed to eat anything other than the hospital meals at least 3 days before urinary sampling.

\section{Statistical analysis}

The data are presented as means \pm s.d. The event frequencies were compared using the $\chi^{2}$ test. Other comparisons between the two groups of data were made with a paired Student's $t$-test. Regression analyses were performed to evaluate the association between changes in blood pressure and changes in salt excretion.

A $P$ value of $<0.05$ was considered to be statistically significant. The JMP statistical software package (version 9, SAS Institute, Cary, NC, USA) was used for the analyses.

\section{RESULTS}

\section{Characteristics of the patients}

After the initial enrolment of 679 outpatients, the data from a second examination were available from 574 patients over 8-26 weeks. Of these patients, 28 with apparent decompensated heart failure and 22 who needed to change medications during follow-up were excluded. Finally, a total of 524 patients ( $72 \pm 10$ year old, 246 female) were included in the analysis. The baseline characteristics of the patients are presented in Table 1. Hypertension was observed in $415(79 \%)$ patients and congestive heart failure in 105 (20\%) patients. Angiotensin-converting enzyme inhibitors/angiotensin receptor blockers were the most commonly prescribed drugs $(60 \%)$, followed by $\mathrm{Ca}$ channel blockers (56\%) and $\beta$-blockers (36\%).

Table 1 Characteristics of the patients $(n=524)$

\begin{tabular}{lc}
\hline Age (year old) & $72 \pm 10$ (38-94) \\
Gender, female/male & $246 / 278$ (female: 47\%) \\
Body mass index $\left(\mathrm{kg} \mathrm{m}^{-2}\right)$ & $24 \pm 3.4(14-39)$ \\
eGFR (ml min ${ }^{-1}$ per $\left.1.73 \mathrm{~m}^{2}\right)$ & $65 \pm 18(13-138)$, eGFR <30:12 (2.3\%) \\
Hypertension & $415(79 \%)$ \\
Diabetes mellitus & $106(20 \%)$ \\
Congestive heart failure & $105(20 \%)$ \\
Old myocardial infarction & $74(14 \%)$ \\
Permanent atrial fibrillation & $67(13 \%)$ \\
& \\
Medications & \\
ACEl/ARBs & $316(60 \%)$ \\
Calcium channel blockers & $296(56 \%)$ \\
$\beta$-blockers & $188(36 \%)$ \\
Diuretics & \\
$\quad$ Loop & $76(14 \%)$ \\
Thiazide & $43(8 \%)$ \\
Aldosterone blockers & $56(11 \%)$ \\
Statins & $220(42 \%)$
\end{tabular}

Abbreviations: ACEI, angiotensin-converting enzyme inhibitor; ARB, angiotensin II receptor blocker; eGFR, estimated glomerular filtration rate.

\section{Changes in daily salt excretion and blood pressure}

Table 2 shows the changes in clinical parameters at the time of enrolment and during the follow-up periods. The daily salt excretion decreased from $9.6 \pm 2.7$ to $8.7 \pm 2.3 \mathrm{~g}$ per day $(P<0.001)$. The proportion of the patients who achieved daily salt excretion to $<6.0$ g per day increased from 7.6 to $11.3 \%(P=0.045)$. The systolic blood pressure decreased from $127.0 \pm 15.4$ to $125.6 \pm 14.5 \mathrm{~mm} \mathrm{Hg}$ $(P=0.026)$, and the diastolic blood pressure decreased from $73.4 \pm 11.0$ to $71.5 \pm 10.8 \mathrm{~mm} \mathrm{Hg}(P<0.001)$. The changes in systolic blood pressure were significantly $(P<0.001)$ associated with the changes in salt excretion, but the correlation was weak $(r=0.16)$, most likely because of the large variability. No relationship was found between the changes in diastolic blood pressure and the changes in salt excretion $(r=0.08, P=0.056)$.

Validation of the method to estimate daily urinary salt excretion from the $\mathrm{Na}$ concentration in spot urine

Urinary samples were obtained from 57 inpatients, whose salt intake could be estimated based on the salt content of their meals, to validate the estimation of their salt intake from spot urine data. Two patients were excluded because one patient could not eat the whole meals and the other ate additional foods. Therefore, 55 patients $(77 \pm 13$ year old, 37 female) were enroled. These patients included 24 individuals with hypertension, 15 with compensated congestive heart failure, 13 with chronic atrial fibrillation 10 with coronary heart disease, 7 with pacemakers and 3 with valvular heart disease, although 12 patients had no apparent cardiovascular disease. Additionally, none of the patients had renal dysfunction and/or renal disease. The amount of salt in the hospital meals was $7.2 \pm 1.4(5-10)$ g per day. There was a positive correlation between the estimated salt excretion and the salt intake calculated based on the hospital meals $(r=0.76, P<0.001)$. The estimated salt excretion calculated by this method was slightly overestimated $(7.7 \pm 1.6 \mathrm{~g}$ per day, $P<0.01)$, but the average difference was slight $(0.5 \pm 1.1$, range: -1.3 to $3.2 \mathrm{~g}$ per day).

\section{DISCUSSION}

This study demonstrated that salt reduction, although only by a small amount, can be accomplished simply through adherence to a physician's instructions to restrict salt, guided by spot urine methods.

Reducing dietary salt is a potentially important therapeutic target for the improvement of public health. ${ }^{1,2}$ A modest dietary salt reduction of $1 \mathrm{~g}$ per day could substantially reduce cardiovascular events. ${ }^{10}$ According to US guidelines, salt intake should be $<5.8 \mathrm{~g}$ per day $(2300 \mathrm{mg} \mathrm{Na})$ in the general population and $<3.8 \mathrm{~g}$ per day $(1500 \mathrm{mg} \mathrm{Na})$ in patients with cardiovascular disease. ${ }^{11}$ The Japanese Society of Hypertension recommended that salt intake should be $<6.0 \mathrm{~g}$ per day, ${ }^{12}$ but the average intake of salt in Japan is $11 \mathrm{~g}$ per day. ${ }^{3-5}$ In addition, reducing salt intake can be difficult in medical practice. Ohta et al. ${ }^{13}$ demonstrated that the rate of achievement of an average urinary salt excretion of $<6 \mathrm{~g}$ per day, with instructions to reduce salt intake from trained dieticians, was only $10.3 \%$, which was similar to the results of the present study (11.3\%). Actually, the average daily salt excretion achieved in this study was $8.7 \mathrm{~g}$ per day, which is much greater than that recommended by several guidelines. $1,11,12$

Assessing salt intake is essential for instructions to reduce salt intake, but it is difficult in practical medicine. An evaluation based on dietary content, determined by a questionnaire or by interviews performed over several days requires detailed calculations by expert dieticians. Thus, this method is often not available in practical medicine and can underestimate salt intake in certain cases because of selective statements by patients. ${ }^{9}$ Estimation by the $\mathrm{Na}$ content in 24 -h pooled urine is reliable 
Table 2 Changes in the clinical parameters

\begin{tabular}{|c|c|c|c|c|}
\hline & At the time of enrolment (range) & Follow-up periods (8-26 weeks) (range) & Change (range) & $\mathrm{P}$ value \\
\hline Salt excretion (g per day) & $9.6 \pm 2.7(3.5-22.1)$ & $8.7 \pm 2.3(3.7-18.0)$ & $-0.9 \pm 2.5(-13.6-6.2)$ & $<0.001$ \\
\hline Male $(n=278)$ & $9.9 \pm 2.6(3.8-22.1)$ & $8.9 \pm 2.3(4.2-18.0)$ & $-1.0 \pm 2.5(-8.5-5.8)$ & $<0.001$ \\
\hline Age $<75$ year old $(n=291)$ & $10.0 \pm 2.6(4.0-22.1)$ & $9.3 \pm 2.2(4.4-18.0)$ & $-0.7 \pm 2.5(-8.5-6.2)$ & $<0.001$ \\
\hline Age $\geqslant 75$ year old $(n=233)$ & $9.2 \pm 2.6(3.5-19.4)$ & $8.0 \pm 2.4(3.7-16.8)$ & $-1.2 \pm 2.6(-13.6-5.3)$ & $<0.001$ \\
\hline Salt excretion $<6.0$ g per day $(n)(\%)$ & $40(7.6)$ & $59(11.3)$ & $19(3.6)$ & 0.045 \\
\hline Diastolic blood pressure $(\mathrm{mm} \mathrm{Hg})$ & $73.4 \pm 11.0(40-106)$ & $71.5 \pm 10.8(50-102)$ & $-1.9 \pm 10.9(-40-34)$ & $<0.001$ \\
\hline
\end{tabular}

and has been used in many clinical trials, ${ }^{3-6}$ but it is also difficult to perform in outpatient daily medical practice because of the inconvenience of collecting urine for $24 \mathrm{~h}$. In contrast, the evaluation of salt intake using the $\mathrm{Na}$ concentration in a spot urine sample is very easy to perform, although its accuracy is not guaranteed. In this study, the average difference between salt excretion and the salt in the hospital meals used in the validation study might have been acceptable $(0.5 \mathrm{~g}$ per day), but it was not in certain individual subjects (maximum difference, $3.2 \mathrm{~g}$ per day). Thus, a salt intake estimation based on data from spot urine can be applied for clinical study to evaluate the influence of changes in salt intake on a relatively stable condition, but it might be too variable to examine an individual's absolute salt intake using only a single measurement. Repeated measurements and repeated instructions on salt restriction might be necessary in real-world practice.

A recently published, large, population-based cohort study showed that cardiovascular events increased in patients in the lowest tertiles of 24-h salt excretion $\left(<7.3 \mathrm{~g}\right.$ per day). ${ }^{6}$ There has been much debate concerning this article and a subsequent Cochrane Review. ${ }^{14-16}$ For example, in the cohort study, ${ }^{6}$ a single 24 -h urine sample, which was used for all of the analysis, could not represent the usual salt intake at the individual level. In addition, there was a high proportion $(33.9 \%)$ of exclusions, mainly due to inadequate urine collections. In the Cochrane meta-analysis of the randomized trials, ${ }^{14}$ one of these trials in heart failure ${ }^{17}$ should not have been included because the participants were severely salt- and water-depleted due to aggressive diuretics therapy (furosemide $250-500 \mathrm{mg}$ twice daily). The optimal salt intake is not clear, at present, but there is no doubt that salt reduction is mandatory in any country in which salt consumption is extremely high, such as Japan.

\section{Limitations}

There are several limitations to this study. First, the estimation of daily urinary salt excretion using a spot urine sample might be less accurate than that using 24-h urine collection, as mentioned above. However, the changes in urinary salt excretion obtained in this study using spot urine were very similar to those assessed with 24-h urine collection by Ohta et al. ${ }^{13}$ (9.6 \pm 4.2 to $8.7 \pm 3.4 \mathrm{~g}$ per day). Second, this study focused on mid-term results, thus the long-term results are not known. Finally, this study was a retrospective analysis of a single-center study. Therefore, prospective multicenter studies and hopefully outcome trials, are needed.

\section{CONCLUSION}

The estimation of salt intake by spot urine was a useful tool for motivating patients to reduce their salt intake; however, achieving salt reduction to the level recommended in the guideline $e^{1,11,12}$ could be a challenge.
1 Appel LJ, Frohlich ED, Hall JE, Pearson TA, Sacco RL, Seals DR, Sacks FM, Smith Jr SC, Vafiadis DK, Van Horn LV. The importance of population-wide sodium reduction as a means to prevent cardiovascular disease and stroke. A call to action from the American Heart Association. Circulation 2011; 123: 1138-1143.

2 He FJ, MacGregor GA. A comprehensive review on salt and health and current experience of worldwide salt reduction programmes. J Hum Hypertens 2009; 23: 363-384.

3 INTERSALT Cooperative Research Group. Intersalt: an international study of electrolyte excretion and blood pressure. Result for 24 hour urinary sodium and potassium excretion. Br Med J 1988; 297: 319-328.

4 Hashimoto T, Fujita Y, Ueshima H, Kagamimori S, Kasamatsu T, Morioka S, Mikawa K, Naruse $\mathrm{Y}$, Nakagawa $\mathrm{H}$, Hara N. Urinary sodium and potassium excretion, body mass index, alcohol intake and blood pressure in three Japanese populations. J Hum Hypertens 1989; 3: 315-321.

5 Nakagawa H, Morikawa Y, Okayama A, Fujita Y, Yoshida Y, Mikawa K, Sakata K, Ishizaki M, Miura K, Naruse $Y$, Kagamimori S, Hashimoto T, Ueshima H. Trends in blood pressure and urinary sodium and potassium excretion in Japan: reinvestigation in the 8th year after the Intersalt Study. J Hum Hypertens 1999; 13: 735-741.

6 Stolarz-Skrzypek K, Kuznetsova T, Thijs L, Tikhonoff V, Seidlerová J, Richart T, Jin Y, Olszanecka A, Malyutina S, Casiglia E, Filipovský J, Kawecka-Jaszcz K, Nikitin Y, Staessen JA. European Project on Genes in Hypertension (EPOGH) Investigators. Fatal and nonfatal outcomes, incidence of hypertension, and blood pressure changes in relation to urinary sodium excretion. JAMA 2011; 305: 1777-1785.

7 Matsuo S, Imai E, Horio M, Yasuda Y, Tomita K, Nitta K, Yamagata K, Tomino Y, Yokoyama H, Hishida A. Collaborators developing the Japanese equation for estimated GFR. Revised equations for estimated GFR from serum creatinine in Japan. Am J Kidney Dis 2009; 53: 982-992.

8 Tanaka T, Okamura T, Miura K, Kadowaki T, Ueshima H, Nakagawa H, Hashimoto T. A simple method to estimate populational 24-h urinary sodium and potassium excretion using a casual urine specimen. J Hum Hypertens 2002; 16: 97-103.

9 Kawano Y, Tsuchihashi T, Matsuura H, Ando K, Fujita T, Ueshima H. Working Group for Dietary Salt Reduction of the Japanese Society of Hypertension. Report of the Working Group for Dietary Salt Reduction of the Japanese Society of Hypertension: (2) Assessment of salt intake in the management of hypertension. Hypertens Res 2007; 10: 887-893.

10 Bibbins-Domingo K, Chertow GM, Coxson PG, Moran A, Lightwood JM, Pletcher MJ, Goldman L. Projected effect of dietary salt reductions on future cardiovascular disease. N Engl J Med 2010; 362: 590-599.

11 Ayala C, Kuklina EV, Peralez J, Keenan NL, Labarthe DRCDC. Application of lower sodium intake recommendations to adults-United States, 1999-2006. MMWR 2009; 58: 281-283.

12 Ogihara T, Kikuchi K, Matsuoka H, Fujita T, Higaki J, Horiuchi M, Imai Y, Imaizumi T, Ito S, Iwao H, Kario K, Kawano Y, Kim-Mitsuyama S, Kimura G, Matsubara H, Matsuura H, Naruse M, Saito I, Shimada K, Shimamoto K, Suzuki H, Takishita S, Tanahashi N, Tsuchihashi T, Uchiyama M, Ueda S, Ueshima H, Umemura S, Ishimitsu T, Rakugi H. Japanese Society of Hypertension Committee. The Japanese Society of hypertension guidelines for the management of hypertension (JSH 2009). Hypertens Res 2009 32: 3-107.

13 Ohta Y, Tsuchihashi T, Onaka U, Eto K, Tominaga M, Ueno M. Long-term compliance with salt restriction in Japanese hypertensive patients. Hypertens Res 2005; 12: 953-957.

14 Taylor RS, Ashton KE, Moxham T, Hooper L, Ebrahim S. Reduced dietary salt for the prevention of cardiovascular disease: a meta-analysis of randomized controlled trials (Cochrane review). Am J Hypertens 2011; 24: 843-853.

15 Labarthe DR, Briss PA. Urinary sodium excretion and cardiovascular disease mortality. JAMA 2011; 305: 1777-1785.

16 He FJ, MacGregor GA. Salt reduction lowers cardiovascular risk: meta-analysis of outcome trials. Lancet 2011; 378: 380-382.

17 Paterna S, Gaspare P, Fasullo S, Sarullo FM, Di Pasquale P. Normal-sodium diet compared with low-sodium diet in compensated congestive heart failure: is sodium an old enemy or a new friend? Clin Sci 2008; 114: 221-230. 